Studia nad Autorytaryzmem i Totalitaryzmem 43, nr 2

Wrocław 2021

https://doi.org/10.19195/2300-7249.43.2.17

\author{
JAKUB ŁAKOMY \\ ORCID: 0000-0002-6655-6787 \\ Uniwersytet Wrocławski \\ jakub.lakomy2@uwr.edu.pl
}

\title{
Koncepcja polityczności Chantal Mouffe a poststrukturalizm w filozofii interpretacji prawniczej
}

Słowa kluczowe: polityczność, autorytaryzm, poststrukturalizm, interpretacja prawa.

\author{
CHANTAL MOUFFE'S CONCEPT OF THE POLITICAL \\ AND POSTSTRUCTURALISM IN THE PHILOSOPHY OF LEGAL INTERPRETATION
}

\begin{abstract}
The present article deals with the political nature of the interpretation theory, using poststructuralism as a source of reflection. The analysis is conducted by using poststructuralist epistemology and poststructuralist political theory. The thesis of this article, which is metatheoretical in nature, is that the poststructuralist concepts of legal interpretation can be used only after simultaneously adopting the assumptions of the political philosophy which originated in poststructuralism. Chantal Mouffe's concept of the political is very much tied to considerations about agonistic democracy and agonistic pluralism, which gives us original answers to the questions of how society, the political system, and the legal system can help us prevent the emergence and flourishing of authoritarianism. The first part of the text presents the poststructuralist definition of the political and politics as well as shows its importance for the analysis of the contemporary legal interpretation concepts. In the next part, the author discusses the topic of poststructuralism in jurisprudence and its most important features for a change in the discourse of philosophy of interpretation. The third part of the article examines poststructuralist anti-essentialism using the example of one from among the most famous neopragmatist and poststructuralist philosophers - Stanley Fish. In the fourth and last part of the considerations, the thesis about the necessity of joint use of poststructuralist epistemology and political theory for research on legal interpretation is verified and metatheoretical conclusions are drawn from it.
\end{abstract}

Keywords: political, populism, authoritarianism, poststructuralism, legal interpretation. 


\section{Pojęcie polityczności — wprowadzenie}

Na początku należy przyjąć pewne rozumienie terminów „polityka” i ,polityczność”, które posłużą do analizy poststrukturalistycznych koncepcji interpretacji prawniczej. Polityczność jest rozumiana poniżej jako „wymiar antagonizmu leżący u podstaw każdego ludzkiego społeczeństwa"1, polityka natomiast jako „zestaw praktyk i instytucji, które w obliczu wprowadzonego przez polityczność konfliktu tworzą porządek umożliwiający ludzkie współistnienie"2. Przez „polityczności interpretacji prawniczej” rozumiem the political w ujęciu Chantal Mouffe. Kluczowe jest dla mnie usytuowanie interpretatora prawa w ramach struktury konfliktów społecznych obecnych w społeczeństwie. Teksty prawne są elementem tła tych konfliktów. Abstrahuję od potocznego wyobrażenia o politycznym uwikłaniu procesów wykładni, jako o związkach interpretatorów z bieżącą polityką w instytucjach legislacyjnych czy w partiach politycznych. Zupełnie poza zakresem mojego zainteresowania znajdzie się empiryczna analiza uwikłania sędziów w „subświecie” polityki³ ${ }^{3}$.

Pomijam często przyjmowane w filozofii prawa i filozofii politycznej rozumienia pojęcia polityki: jako „działań zmierzających do udziału we władzy lub wywierania wpływu na jej podział między [...] państwem, jednostkami i organizacjami [...] z odwołaniem się do przemocy” "4 oraz jako „działalność celową, sztukę lub zracjonalizowaną umiejętność podejmowania decyzji w sferze publicznej”, która wypływa z Arystotelesowskich rozważań o dobru wspólnym 5 .

Tezą niniejszego tekstu, mającego charakter metateoretyczny, jest wykazanie, że posługiwanie się poststrukturalistycznymi koncepcjami interpretacji prawniczej jest możliwe dopiero po przyjęciu precyzyjnych narzędzi filozofii polityki, również o poststrukturalistycznym rodowodzie. Na gruncie jurysprudencji bardzo rzadko rozpatruje się problematykę epistemologiczną, metodologiczną, równolegle z siatką pojęciową filozofii polityki. W przypadku badania koncepcji filozofii interpretacji prawniczej mających rodowód poststrukturalistyczny jest to niezbędne.

Koncepcja polityczności Chantal Mouffe jest bardzo mocno związana z rozważaniami o demokracji agonistycznej oraz o pluralizmie agonistycznym. Jak

${ }^{1}$ Ch. Mouffe, Polityczność. Przewodnik „,Krytyki Politycznej”, Warszawa 2008, s. 24.

2 Ibidem.

3 Szerzej o polityczności w ujęciu Mouffe zob. M. Paździora, M. Stambulski, Co może dać nauce prawa polityczność? Przyczynek do przyszłych badań, „Archiwum Filozofii Prawa i Filozofii Społecznej” 2014, nr 1, s. 55 n. Por. A. Bator, J. Łakomy, Pojęciowe uwarunkowania badań nad zwiazkami prawa i polityki, „Przegląd Prawa i Administracji” 122, Wrocław 2020, s. 16-17; A. Sulikowski, R. Mańko, J. Łakomy, Introduction, [w:] Legal Scholarship and the Political. In Search of a New Paradigm, red. A. Sulikowski, R. Mańko, J. Łakomy, Warszawa 2020, s. XI n.

4 A. Bator, Polityczne interpretacje analitycznej teorii prawa, [w:] Integracja zewnętrzna i wewnętrzna nauk prawnych, cz. 1, red. M. Zirk-Sadowski, B. Wojciechowski, T. Bekrycht, Łódź 2014, s. 14.

\section{Ibidem.}


wykazywano w literaturze, koncepcje te dają nam oryginalne odpowiedzi na pytanie, w jaki sposób społeczeństwo, system polityczny i system prawny mogą nam pomóc zapobiegać powstawaniu i rozkwitowi autorytaryzmów 6 .

\section{Poststrukturalizm a wykładnia prawa}

Używanie poststrukturalistycznej definicji polityczności jest naturalnym wyborem, spójnym ze sposobem myślenia o epistemologii przyjmowanym poniżej. Dyskurs epistemologii i filozofii polityki łączy się wyraźnie w Nietzscheańskich perspektywizmie i interpretacjonizmie ${ }^{7}$. Stanowiska te zakładają, że wszystko jest interpretacją, a my nie mamy wglądu w prawdę obiektywną. Zderzenie odmiennych perspektyw, epistemologicznie rzecz biorąc, nie może być rozstrzygnięte na gruncie ontologicznym i metodologicznym. Na poziomie społecznym (oraz prawnym) jesteśmy uczestnikami ,agonu”, bronimy prawd, do których docieramy z naszych osobistych perspektyw ${ }^{8}$. Agon ów znajduje również odzwierciedlenie w sferze ścierania się sprzecznych interesów, gdzie spory perspektyw motywowane są politycznie.

Niniejszy artykuł jest głosem w dyskusji, jaką poststrukturalistyczne nurty filozofii prowadzą od dziesięcioleci z filozofią analityczną, która stanowi podstawę wielu klasycznych pozytywistycznych teorii interpretacji prawniczej. Moja argumentacja jest prowadzona z perspektywy obozu krytyków analitycznych teorii znaczenia tekstu i metodologii czytania tekstów na nich wyrosłych. Przełom poststrukturalistyczny miał znaczący wpływ na teorie prawa i teorie interpretacji prawniczej; pod jego wpływem ukształtowało się kilka bardzo oryginalnych nurtów w ogólnej refleksji nad prawem ${ }^{9}$. Przełom poststrukturalistyczny oznaczał radykalne wprowadzenie problematyki polityczności do namysłu nad interpretacją prawa i dał badaczom prawa narzędzia, koncepcje i język do ujawniania problematyki uwikłania politycznego samych procesów interpretacji prawniczej. Należy podkreślić, że poststrukturalizm doprowadził do powiązania kwestii semantycznych z politycznością. Poststrukturaliści wierzyli, że poprzez dekonstrukcje

${ }^{6}$ Por. na przykład A. Sulikowski, Demoliberalizm, populizm, autorytaryzm. Kryzys hegemonii i poszukiwanie (nowego) prawniczego logosu, „Studia nad Autorytaryzmem i Totalitaryzmem” 42, 2020, nr 3, s. 43-44

7 M.P. Markowski, Nietzsche. Filozofia interpretacji, Kraków 2001, passim.

${ }^{8}$ O takiej perspektywie i o koncepcji hermeneutycznego uniwersalizmu, która jest elementem tła w niniejszych rozważaniach, pisałem szczegółowo między innymi w: J. Łakomy, Polityczność (teorii) wykładni prawa. Perspektywa neopragmatyzmu Stanleya Fisha, „Archiwum Filozofii Prawa i Filozofii Społecznej” 2018, nr 3, s. 24-37; idem, Hermeneutic universalism: a post-analytical inquiry into the political of legal interpretation, [w:] A post-analytical approach to philosophy and theory of law, red. A. Bator, Z. Pulka, Berlin 2019, s. 39-56.

9 Zob. na przykład A. Sulikowski, Współczesny paradygmat sądownictwa konstytucyjnego wobec kryzysu nowoczesności, Wrocław 2008, s. 149 n. 
powszechnie przyjmowanych znaczeń podważają fundamenty opresywnego systemu politycznego. Polityczny charakter miała zarówno dekonstrukcyjna lektura tekstów, jak i formułowanie teoretycznych tez dotyczących samego procesu lektury. Filozofia interpretacji tekstów z natury rzeczy musiała być zatem polityczna.

Pokazując niestabilność znaczenia i niemożność zakotwiczenia odniesienia, poststrukturaliści kierowali naszą uwagę na to, że dokonując interpretacji tekstów z konieczności dokonujemy jednocześnie aktów stricte politycznych. Jeśli mamy pewne narzędzia, pozwalające nam demaskować ideologie, które skrystalizowały się $\mathrm{w}$ postaci hegemonii spopularyzowanych znaczeń, utrzymujących status $q u o$, to sama demaskacja, dekonstrukcja będzie aktem politycznym per se. Rola i zadania poststrukturalistycznej teorii interpretacji będą zatem odmienne od teorii klasycznej. Niektóre jej wersje będą bardziej aktywistyczne, dążące do zmian prawnych i społecznych, inne bardziej deskrypcyjne, opisujące praktykę i jej polityczne uwikłania. Tym, co połączy różne wersje poststrukturalistycznej teorii, będzie sprzeciw wobec budowania teorii normatywnej, w takich wersjach, które dają interpretatorowi pewien uporządkowany zbiór dyrektyw, mający pomóc mu dotrzeć do właściwego, obiektywnego znaczenia tekstu. Poniżej zaprezentowana zostanie jedna $\mathrm{z}$ wersji poststrukturalistycznej teorii interpretacji.

\section{Antyesencjalizm Stanleya Fisha jako przykład poststrukturalizmu w teorii interpretacji}

Przykładem filozofii intepretacji prawniczej, która uwewnętrznia poststrukturalistyczną koncepcję procesów poznawania tekstów, jest koncepcja amerykańskiego neopragmatystycznego filozofa interpretacji literackiej i prawniczej Stanleya Fisha ${ }^{10}$. Na polityczne implikacje antyesencjalistycznego stanowiska Fisha zwraca uwagę Richard Rorty we wstępie do polskiego przekładu esejów Interpretacja, retoryka, polityka ${ }^{11}$. Rorty wskazuje tam jeden z fragmentów pism Fisha, cytując esej No bias, no merit ze zbioru Doing What Comes Naturally:

Krótko mówiąc, to, co istotowe, jest kategorią raczej polityczną niż esencjalną i jako taka zawsze będzie ona odzwierciedlać nasze interesy — w sposób całkowicie uprawniony, ponieważ bez interesów nie byłoby także żadnych wartości - tych, którzy przyłożyli rękę do jej ukształtowania. W tym czasie interesy innych zostaną wykluczone czy zlekceważone, a grupy te będą najczęściej protestować przeciwko ich wykluczeniu w imię inherentnych własności. Lecz to, co będą naprawdę czynić, to próbować zastąpić kogoś innego, pojęcie inherentnej własności, swoim własnym ${ }^{12}$.

10 Pisałem o niej szerzej między innymi w: J. Łakomy, Polityczność (teorii) wykładni...

11 R. Rorty, Wstęp do polskiego wydania wyboru esejów Stanleya Fisha, [w:] S. Fish, Interpretacja, retoryka, polityka, Kraków 2008, s. 5 n.

12 S. Fish, No bias, no merit, [w:] idem, Doing What Comes Naturally, Durham 1989, s. 174; przeł. A. Szahaj, [w:] S. Fish, Interpretacja, retoryka, polityka, s. 8. Tłumaczenie zmodyfikowane - J.E. 
Rorty wpisuje teorię interpretacji Fisha w szerszy antyplatoński, antymetafizyczny projekt filozoficzny, sytuując poglądy swojego neopragmatystycznego towarzysza obok Heideggera, Derridy, Wittgensteina, Quine'a, Hume'a, Brandoma czy Kuhna. Antyplatoński charakter takiej odmiany antymetafizycznego neopragmatyzmu polega na przyznaniu, że powinniśmy porzucić wysiłki poszukiwania „precyzyjnego, literalnego znaczenia wyrażeń językowych”, gdyż „nigdy nie zdołamy wyjść [...] poza politykę ku czemuś mniej lokalnemu i przygodnemu". Projekt Fisha jest również sytuowany w ramach utopijnej kultury, gdzie, jak chciał Nietzsche, nie będzie faktów, a jedynie interpretacje ${ }^{13}$.

Antyplatońskie myślenie w sferze interpretacji wychodzi z ogólniejszego założenia ontologicznego, że nie istnieją esencje, byty pozaludzkie, które mogłyby być twardymi i obiektywnymi punktami odniesienia, do których moglibyśmy się odwołać, aby rozwiązywać spory między nami. To ludzie, kultura czy wspólnoty interpretacyjne są według Rorty’ego jedynym i ostatecznym źródłem władzy. Paradoksalnie, w momencie gdy twierdzimy, że możemy mieć kontakt z takim ponadkontekstualnym bytem, dokonujemy również pewnego politycznego zabiegu. W sferze interpretacji prawniczej, jeśli uzyskujemy rzekomo „obiektywny rezultat wykładni prawa”, ,znaczenie literalne tekstu”, w istocie mamy do czynienia jedynie $\mathrm{z}$ wynikiem pewnego procesu politycznego. Rezultat interpretacji prawniczej, ,znaczenie literalne”, zyskało takie miano w wyniku aktu interpretacji, który został zaakceptowany dzięki skutecznej perswazji (lub aktu hegemonicznego, jeśli spoglądamy na ten proces przy użyciu poststrukturalistycznych ujęć polityczności).

To, że poszczególne wspólnoty interpretacyjne, których jesteśmy członkami, są umieszczone na „mapie” konfliktów społecznych sprawia, iż konkretne akty interpretacji członków owych wspólnot są polityczne per se — ,polityczne” w rozumieniu the political właśnie. Możemy wyprowadzić wniosek, że członkowie wspólnot interpretacyjnych, usytuowani w społeczeństwie w ramach grup społecznych, posiadający odmienne interesy, odmiennie kategoryzujący Mouffe'owskich oponentów w radykalnej demokracji liberalnej (demokracji agonistycznej), rozgrywają jeden z najistotniejszych agonizmów we współczesnych, zjurydyzowanych systemach społeczno-politycznych.

\section{Podsumowanie - polityczność filozofii interpretacji}

Na zakończenie spójrzmy na poniższe tezy Chantal Mouffe:

Wtedy, gdy uznamy „to, co polityczne” w jego antagonistycznym wymiarze, będziemy mogli postawić kluczowe dla demokratycznej polityki pytanie. I nie brzmi ono, z całym szacunkiem dla liberalnych teoretyków, w jaki sposób powinniśmy negocjować kompromis pomiędzy konkurującymi interesami, ani też jak osiągnąć „racjonalny”, to jest w pełni inkluzywny kon-

13 R. Rorty, Wstęp do polskiego wydania..., s. 8. 
sensus, konsensus bez żadnego wykluczenia. Polityka wiąże się z tworzeniem jakiegoś „my”, a to wymaga odróżnienia od jakiegoś „oni”. Wbrew temu, w co chciałoby, abyśmy uwierzyli wielu liberałów, specyfiki polityki demokratycznej nie stanowi przekroczenie podziału myoni, lecz inny sposób jego ustanawiania. Tym, czego demokracja wymaga, jest wytyczanie podziału my-oni w sposób zgodny z uznaniem roli pluralizmu, będącym istotą nowoczesnej demokracji ${ }^{14}$.

Jeśli skonfrontujemy z sobą te stanowiska - pojmowanie interpretacji przez poststrukturalistów, kulturalistyczne, konstruktywistyczne spojrzenie neopragmatystów i poststrukturalną teorię społeczną i polityczną, będziemy zmuszeni wyprowadzić wnioski, które, na gruncie teorii interpretacji prawniczej, zmuszą nas do odrzucenia wielu tez zarówno pozytywistycznej, jak i hermeneutycznej (czy też konsensualnej — porawlsowskiej, habermasowskiej) jurysprudencji; zmusi nas to też do całkowitej rekonceptualizacji relacji między prawem a polityką. Przede wszystkim każdy prawnik, każdy interpretator będzie musiał zdać sobie sprawę, że wszelkie spory sądowe są również w określony sposób wpisane w szersze, makrospołeczne konflikty. Będzie musiał zdać sobie sprawę, że problematyka poznania - ustalania znaczenia tekstu, brania pod uwagę kontekstu funkcjonowania prawa - wymaga uwzględnienia perspektyw wszystkich stron biorących udział w sporze. Moment uświadomienia sobie głębszych, społecznych implikacji konfliktu sądowego, jest momentem, w którym zdamy sobie sprawę z politycznego charakteru procesu ustalania znaczenia prawa (oraz teorii, która daje nam wskazówki, jak prawo interpretować). Właśnie dlatego dyskurs epistemologiczny, metodologiczny przenika się z tezami i pojęciami filozofii polityki ${ }^{15}$.

Oddajmy raz jeszcze na koniec głos Mouffe:

Uznanie wymiaru tego, co polityczne, jako stale obecnej możliwości antagonizmu pociąga za sobą konieczność pogodzenia się z brakiem ostatecznego ugruntowania, z nierozstrzygalnością przenikającą każdy ład. Oznacza to uznanie hegemonicznej natury każdego ładu społecznego oraz faktu, że każde społeczeństwo jest wytworem systemu praktyk zmierzających do ustanowienia ładu w warunkach przygodności. Domena tego, co polityczne, powiązana jest $\mathrm{z}$ aktami hegemonicznego ustanawiania ${ }^{16}$.

Akceptacja poststrukturalizmu w teorii poznania powinna nas skłonić do tego, aby powyższe stwierdzenie odnosić nie tylko do analizy problemów społecznych i politycznych, ale w równym stopniu do analizy praktyk stosowania prawa oraz teorii interpretacji prawniczej. Brak ostatecznego ugruntowania i nierozstrzygalność

$14 \mathrm{https}$ ///recyklingidei.pl/mouffe-agonistyczne-przestrzenie-publiczne-polityka-demo kratyczna (dostęp: 29.06.2021).

15 Por. na przykład R. Mańko, Judicial Decision-Making, Ideology and the Political: Towards an Agonistic Theory of Adjudication, „Law and Critique” 2021, passim, https://doi.org/10.1007/s10 978-021-09288-w (dostęp: 30.06.2021).

$16 \mathrm{https}$ ///recyklingidei.pl/mouffe-agonistyczne-przestrzenie-publiczne-polityka-demo kratyczna (dostęp: 29.06.2021). 
przenikająca każdy ład społeczno-prawny musi być brany pod uwagę, kiedy konceptualizujemy i operacjonalizujemy jakąkolwiek teorię wykładni prawa.

\section{Bibliografia}

Bator A., Łakomy J., Pojęciowe uwarunkowania badań nad zwiąkami prawa i polityki, „Przegląd Prawa i Administracji” 122, 2020.

Bator A., Polityczne interpretacje analitycznej teorii prawa, [w:] Integracja zewnętrzna i wewnętrzna nauk prawnych, cz. 1, red. M. Zirk-Sadowski, B. Wojciechowski, T. Bekrycht, Łódź 2014.

Fish S., Interpretacja, retoryka, polityka, Kraków 2008.

Fish S., No bias, no merit, [w:] idem, Doing What Comes Naturally, Durham 1989.

Łakomy J., Hermeneutic universalism: a post-analytical inquiry into the political of legal interpretation, [w:] A post-analytical approach to philosophy and theory of law, red. A. Bator, Z. Pulka, Berlin 2019.

Łakomy J., Polityczność (teorii) wyktadni prawa. Perspektywa neopragmatyzmu Stanleya Fisha, „Archiwum Filozofii Prawa i Filozofii Społecznej” 2018, nr 3.

Mańko R., Judicial Decision-Making, Ideology and the Political: Towards an Agonistic Theory of Adjudication, „Law and Critique” 2021, https://doi.org/10.1007/s10978-021-09288-w.

Markowski M.P., Nietzsche. Filozofia interpretacji, Kraków 2001.

Mouffe Ch., Agonistyczne przestrzenie publiczne i polityka demokratyczna, https://recyklingidei.pl/ mouffe-agonistyczne-przestrzenie-publiczne-polityka-demokratyczna.

Mouffe Ch., Polityczność. Przewodnik „Krytyki Politycznej”, Warszawa 2008.

Paździora M., Stambulski M., Co może dać nauce prawa polityczność? Przyczynek do przyszłych badań, „Archiwum Filozofii Prawa i Filozofii Społecznej” 2014, nr 1.

Sulikowski A., Demoliberalizm, populizm, autorytaryzm. Kryzys hegemonii i poszukiwanie (nowego) prawniczego logosu, „Studia nad Autorytaryzmem i Totalitaryzmem” 42, 2020, nr 3.

Sulikowski A., Wspótczesny paradygmat sądownictwa konstytucyjnego wobec kryzysu nowoczesności, Wrocław 2008.

Sulikowski A., Mańko R., Łakomy J., Introduction, [w:] Legal Scholarship and the Political. In Search of a New Paradigm, red. A. Sulikowski, R. Mańko, J. Łakomy, Warszawa 2020. 